\title{
Androgen insensitivity syndrome
}

leuan A Hughes, John D Davies, Trevor I Bunch, Vickie Pasterski, Kiki Mastroyannopoulou, Jane MacDougall

Androgen insensitivity syndrome in its complete form is a disorder of hormone resistance characterised by a female phenotype in an individual with an XY karyotype and testes producing age-appropriate normal concentrations of androgens. Pathogenesis is the result of mutations in the X-linked androgen receptor gene, which encodes for the ligand-activated androgen receptor-a transcription factor and member of the nuclear receptor superfamily. This Seminar describes the clinical manifestations of androgen insensitivity syndrome from infancy to adulthood, reviews the mechanism of androgen action, and shows examples of how mutations of the androgen receptor gene cause the syndrome. Management of androgen insensitivity syndrome should be undertaken by a multidisciplinary team and include gonadectomy to avoid gonad tumours in later life, appropriate sex-hormone replacement at puberty and beyond, and an emphasis on openness in disclosure.

\section{Introduction}

Several clinical disorders arise because of complete or partial resistance to the action of hormones. ${ }^{1}$ Examples include diabetes due to insulin resistance ${ }^{2}$ and reproductive disorders caused by resistance to gonadotropin and steroid hormones. ${ }^{3}$ Male development during fetal life occurs only when an XY zygote directs the bipotential gonad to become a testis (sex determination), which in turn secretes sufficient amounts of active androgen to produce the male phenotype (sex differentiation). ${ }^{4}$ Figure 1 shows the pathway of healthy male and female fetal sex development, modified to include complete resistance to the action of androgens resulting in a female phenotype-ie, a hormoneresistance syndrome.

Hormone-resistance syndrome was fully characterised by John Morris, who reviewed the clinical features of 82 patients. ${ }^{5}$ Because the patients were women and girls with bilateral testes that seemed to produce oestrogen-like hormones, Morris coined the term testicular feminisation syndrome. This contradictory label was renamed as complete androgen insensitivity syndrome, which is now the accepted terminology. ${ }^{6}$ Partial androgen insensitivity syndrome refers to a phenotype of varying degrees of masculinisation of the external genitalia due to partial androgen responsiveness. Mild androgen insensitivity syndrome is reported in healthy men and boys who can present with adolescent gynaecomastia or infertility in later life. Thus, androgen insensitivity syndrome can be defined as a disorder resulting from complete or partial resistance to the biological actions of androgens in an $\mathrm{XY}$ man or boy with normal testis determination and production of age-appropriate androgen concentrations. The pathophysiology of this syndrome is based on the mechanism of action of androgens (appendix).

\section{Complete androgen insensitivity syndrome Clinical presentation}

The typical presentation for complete androgen insensitivity syndrome is either primary amenorrhoea in adolescence, or inguinal swellings in an infant. A female adolescent with the disorder has breast development and a pubertal growth spurt at the appropriate age, but no menses. Development of oestrogen-dependent secondary sexual characteristics occurs as the result of excess aromatisation of androgens. Pubic and axillary hair is usually absent or can be present in sparse amounts. No precise figures are available for the prevalence of complete androgen insensitivity syndrome, but estimates range from one in 20400 to one in 99100 genetic males on the basis of a proven molecular diagnosis.?

In infancy, complete androgen insensitivity syndrome presents as an inguinal hernia or labial swelling containing a testis in an apparently female infant. Bilateral inguinal herniae are rare in female infants-the incidence of complete androgen insensitivity syndrome in such patients is $1-2 \%$ during infancy. ${ }^{8,9}$ Clinicians recommend that karyotyping or a biopsy of a gonad within the hernial sac is done after the parents give consent. ${ }^{10}$ Alternatively, vaginal length can be measured in prepubertal girls undergoing inguinal hernia repair to screen for complete androgen insensitivity syndrome; ${ }^{9}$ a shortened vagina and the absence of ovaries or fallopian tubes suggests the need for karyotyping. The uterus, cervix, and proximal vagina are absent in complete androgen insensitivity syndrome because of the action of antimüllerian hormone produced by Sertoli cells of the testis. ${ }^{4}$ The vagina varies from a dimple in the perineum to normal length, but is always blind-ending. Occasionally, older sisters of people with complete androgen insensitivity syndrome have also had

\section{Search strategy and selection criteria}

We searched PubMed mainly with the search terms "androgen insensitivity syndrome" in combination with the additional terms "complete" and "partial". For the molecular section, we searched for the terms "androgen receptor", "androgen receptor mutation", "nuclear receptor", and "nuclear receptor co-regulators". For the management section, we used the terms "germ cell tumours", "hormone replacement therapy", "vaginal dilators", and "gender identity". We selected publications from the past 10 years, but older papers related to first descriptions of the syndrome are cited, as are relevant review articles from monographs and book chapters.
Lancet 2012; 380: 1419-28 Published Online June 13, 2012 http://dx.doi.org/10.1016/ S0140-6736(12)60071-3

Department of Paediatrics, University of Cambridge, Cambridge, UK (Prof I A Hughes MD, J D Davies PhD, TI Bunch, $\checkmark$ Pasterski PhD, K Mastroyannopoulou $\mathrm{BSc}$ ); and Section of Reproductive Medicine, Department of Obstetrics and Gynaecology, Addenbrooke's Hospital, Cambridge, UK (J MacDougall MD) Correspondence to: Prof leuan A Hughes, Department of Paediatrics, University of Cambridge, Addenbrooke's Hospital, Hills Road, Cambridge CB2 OQQ, UK iah1000@cam.ac.uk

See Online for appendix 


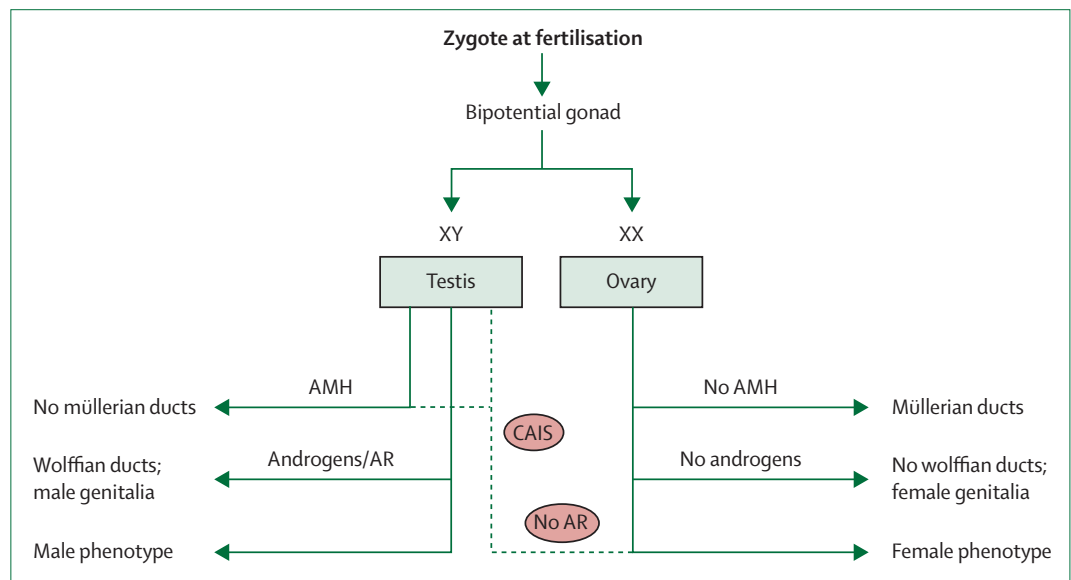

Figure 1: Simplified pathway of fetal sex development

$\mathrm{AR}=$ androgen receptor. $\mathrm{CAIS=complete}$ androgen insensitivity syndrome. $\mathrm{AMH}=$ antimüllerian hormone.

an inguinal hernia repair in infancy, and can have a 46,XY karyotype (unpublished).

Diagnosis of complete androgen insensitivity syndrome can happen by chance. The sex of a fetus is now increasingly known before birth through analysis of karyotypes, chorionic villi, amniotic fluid samples, or maternal circulating free fetal DNA, ${ }^{11}$ and use of threedimensional ultrasonography. Complete androgen insensitivity syndrome can therefore sometimes be diagnosed as a result of mismatch between the prenatal sex prediction and the phenotype at birth. ${ }^{12}$ Other modes of presentation include a known family history of X-linked complete androgen insensitivity syndrome and, occasionally, the discovery of a pelvic mass arising from a gonadal tumour. ${ }^{13}$

Adult women with complete androgen insensitivity syndrome are generally taller than women without the syndrome, but are on average shorter than the male population..$^{14}$ Patients in whom gonadectomy is delayed are even taller, suggesting a relative oestrogen deficiency before gonadectomy. ${ }^{15}$ However, no evidence shows that girls with complete androgen insensitivity syndrome start puberty later than girls without the syndrome. ${ }^{16}$ The enlarged adult stature in the syndrome is mainly due to the effect of the growth-controlling region on the long arm of the Y chromosome, but genome-wide association studies have identified several loci that affect adult height. ${ }^{17}$ Infants with complete androgen insensitivity syndrome are on average the same size at birth as male infants, suggesting that factors on the $\mathrm{Y}$ chromosome rather than exposure to prenatal androgens explain the sex dimorphism. ${ }^{18}$

\section{Endocrine features}

Women with complete androgen insensitivity syndrome who have intact gonads have the endocrine profile of a hormone-resistant state. Serum testosterone concentrations are either within or above the normal range for men and boys and luteinising hormone (LH) concentrations are inappropriately increased..$^{19}$ Concentrations of follicle-stimulating hormone and inhibin are generally normal. Excess testosterone is produced and peripherally aromatised to oestrogen which, together with LH-induced direct secretion of testicular oestrogen, results in serum oestradiol concentrations higher than those noted in men and boys but lower than those reported in women without complete androgen insensitivity syndrome. ${ }^{20}$ Serum gonadotropin concentrations increase further after gonadectomy, but are only partly suppressed with oestrogen substitution. These findings suggest resistance to the negative-feedback effect of androgens on hypothalamic-pituitary control of gonadotropin secretion in complete androgen insensitivity syndrome, but maintenance of a partial negative feedback by oestrogens. Concentrations of sexhormone-binding globulin are sexually dimorphic; androgens decrease and oestrogens increase hepatic production, respectively. Concentrations of this protein in patients with complete androgen insensitivity syndrome are similar to those in women without the syndrome and do not decrease after androgen administration. ${ }^{21}$

The pattern of gonadotropin and testosterone concentrations is less suggestive of hormone resistance when complete androgen insensitivity syndrome presents in infancy. ${ }^{22,23}$ Usually, LH-induced serum testosterone concentrations surge during the first few months of life-a so-called mini-puberty. ${ }^{24,25}$ This profile, however cannot be used to diagnose complete androgen in sensitivity syndrome in many infants, although serum testosterone concentrations do increase appropriately after stimulation with human chorionic gonadotropin. ${ }^{22}$ Infants with partial androgen insensitivity syndrome have a more responsive pattern of LH and testosterone, both basally and after stimulation with human chorionic gonadotropin. The human chorionic gonadotropin stimulation test is key to exclusion of other causes that give rise to a similar phenotype.

Low testosterone concentrations in infants with complete androgen insensitivity syndrome are not fully understood but might suggest that androgens need to act prenatally on the hypothalamic-pituitary axis to prime the LH surge after birth. Serum antimüllerian hormone concentrations also rise in the neonatal period and are sexually dimorphic. ${ }^{24,26,27}$ Serum antimüllerian hormone measurement not only suggests the presence of testes in complete androgen insensitivity syndrome, but also that concentrations are higher in infants with the syndrome than in male infants. ${ }^{28}$ Concentrations of testosterone and antimüllerian hormone are inversely associated during male puberty, but this relation does not hold during the so-called mini-puberty of infancy. This discrepancy occurs because androgen receptors are not expressed in Sertoli cells of the infant testis, suggesting a state of transient androgen insensitivity in Sertoli cells 
during the fetal and neonatal stages of testis development. ${ }^{29}$ This insensitivity is amplified in complete androgen insensitivity syndrome, resulting in even higher concentrations of antimüllerian hormone, which distinguishes the syndrome from complete gonadal dysgenesis, a disorder of impaired Sertoli cell function.

The differential diagnosis for complete androgen insensitivity syndrome in female adolescents includes other causes of primary amenorrhoea such as complete gonadal dysgenesis, ${ }^{30}$ Mayer-Rokitansky-Kuster-Hauser syndrome, and other müllerian duct anomalieseg, transverse vaginal septae. Other differential diagnoses include various androgen biosynthesis disorders (appendix). ${ }^{31}$

\section{Partial androgen insensitivity syndrome}

The clinical presentation of partial androgen insensitivity syndrome depends on the degree of responsiveness of the external genitalia to androgens. The typical phenotype is micropenis, severe hypospadias (perineoscrotal), and a bifid scrotum that might contain gonads. Occasionally, the appearance of the genitalia is more consistent with complete androgen insensitivity syndrome, apart from the degree of clitoromegaly. This presentation is referred to as severe partial androgen insensitivity syndrome, and sex assignment is generally female. Panel 1 lists the causes of undermasculinised men and boys with phenotypes similar to that of partial androgen insensitivity syndrome. Extensive genetic and biochemical investigations are needed to confirm diagnosis. Workers have reported guidance on how to investigate partial androgen insensitivity syndrome and other disorders of sex development presenting at birth or in adolescence. ${ }^{32}$ Hypospadias is a common male congenital malformation (prevalence up to eight cases per 1000 births) that is often associated with low birthweight of unknown cause. ${ }^{33}$ Sequencing of the androgen receptor gene to identify an abnormal receptor is needed for a firm diagnosis of partial androgen insensitivity syndrome. If possible, an in-vitro functional assay should be done to confirm pathogenicity.

\section{Mild androgen insensitivity syndrome}

Mild androgen insensitivity syndrome is associated with a mutation of the androgen receptor gene and is infrequently reported. It presents in men as infertility but is not associated with genital anomalies. ${ }^{34}$ Fertility is possible if the sperm count can be restored after highdose androgen treatment. ${ }^{35}$ The product of serum LH and testosterone concentrations as an index of possible mild androgen insensitivity syndrome in infertile men could be a useful screening test for the presence of a mutation in the androgen receptor gene. The results of conditional knockout experiments of the androgen receptor in mice show that a functional receptor expressed in Sertoli and Leydig cells is essential for normal spermatogenesis. ${ }^{36}$
Panel 1: Causes of a PAIS-like phenotype

Defects in androgen production

- Partial gonadal dysgenesis

- Mutations in SRY, NR5A1, WT1

- Mutations of the luteinising hormone receptor

- Biosynthetic enzyme deficiencies

- 17,20-lyase deficiency

- P450 oxidoreductase deficiency

- $17 \beta$-hydroxysteroid dehydrogenase deficiency type 3

- $5 \alpha$-reductase deficiency type 2

Genetic

- Klinefelter's syndrome

- Smith-Lemli-Opitz syndrome

- Denys-Drash syndrome

- Frasier's syndrome

\section{PAIS}

- Mutations of the androgen receptor gene

- Normal androgen receptor gene with fetal growth restriction

PAIS=partial androgen insensitivity syndrome. $S R Y=$ sex-determining region $Y$. NR5A1=nuclear receptor subfamily 5 A1. WT1=Wilms' tumour 1.

Mild androgen insufficiency syndrome can also manifest as bulbar and spinal muscular atrophy (Kennedy's disease). ${ }^{37}$ In addition to the characteristic weakness and wasting of bulbar, facial, and limb muscles, patients with this neurological disorder have increased testosterone concentrations that are associated with gynaecomastia and reduced fertility, which is consistent with mild androgen insensitivity. The pathogenesis of bulbar and spinal muscular atrophy is associated with hyperexpansion of the CAG repeat (more than 38) in exon 1 of the androgen receptor gene, leading to a toxic gain of function. ${ }^{38}$ Experiments in which transgenic mice with hyperexpanded CAG repeats were crossed with mice with inactive androgen receptors showed increased deleterious neuromuscular and endocrine-reproductive features. ${ }^{39}$ Variation in the number of CAG repeats within the normal ranges is associated with several androgen-related disorders such as polycystic ovary syndrome, male infertility, male pattern baldness, metabolic syndrome, and prostate cancer, and even with growth during childhood in boys. ${ }^{40}$ Such associations alone are unlikely to have much clinical relevance, but the number of CAG repeats can have modulatory effects on the phenotypic manifestation of some mutations of the androgen receptor gene noted in partial androgen insensitivity syndrome, particularly when the phenotype varies with the same mutation. ${ }^{41}$

\section{Molecular pathogenesis}

In complete and partial androgen insensitivity syndrome, mis-sense mutations are distributed throughout the eight exons of the androgen receptor gene, but localised mainly in exons that encode the 


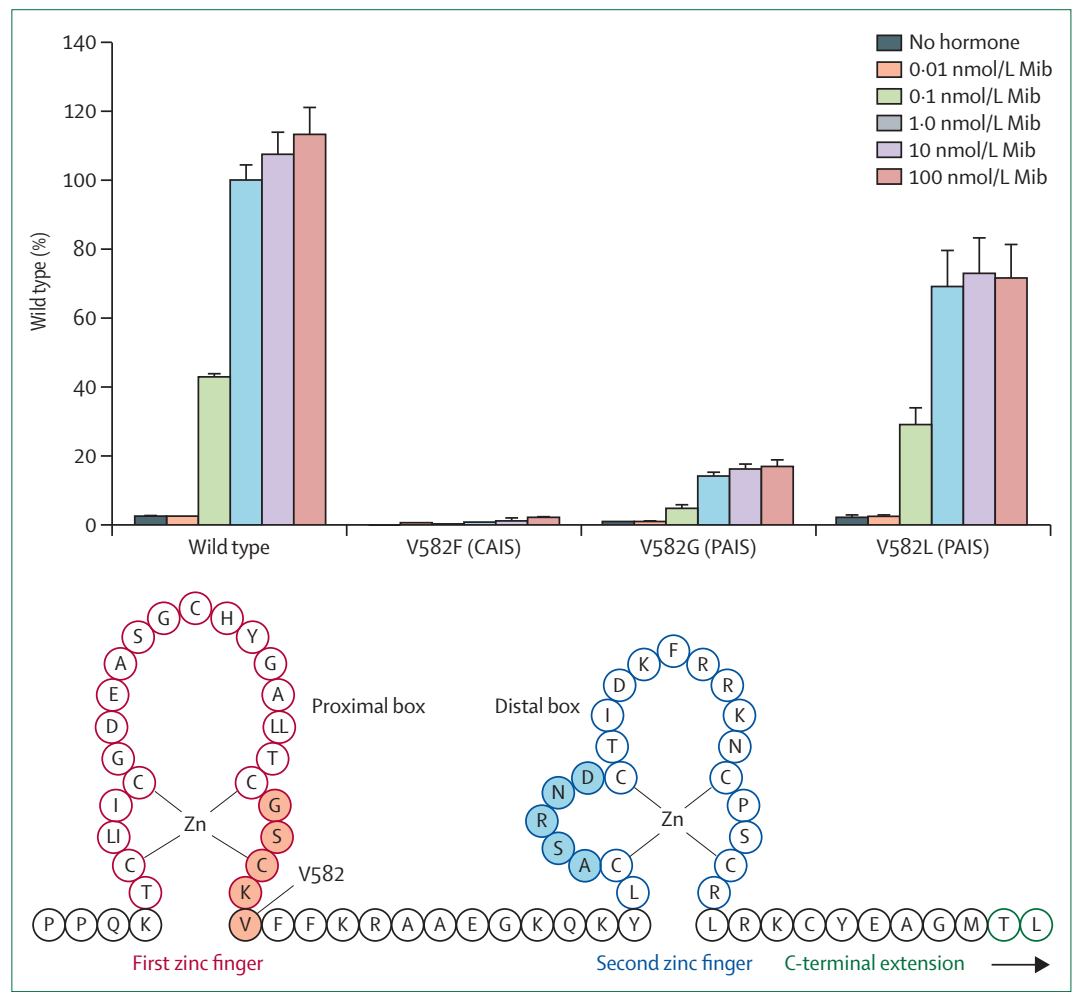

Figure 2: Mutations in the DNA-binding domain first zinc finger

The effects of substitution of a valine (V) at codon 582 in the DNA-binding domain with phenylalanine (F), glycine $(G)$, and leucine $(L)$ are shown in a transactivation assay with the synthetic androgen mibolerone. Responsiveness of the reporter gene is related to a complete or partial androgen insensitivity syndrome phenotype. The linear stretch of aminoacids comprising the DNA-binding domain is also shown. Mib=mibolerone. CAIS=complete androgen insensitivity syndrome. PAIS=partial androgen insensitivity syndrome.

DNA-binding and ligand-binding domains where their functional effect is great because of the ordered structure of these domains (appendix). ${ }^{42}$

Genital skin fibroblasts express androgen receptors in high concentrations and can be used to measure androgen binding when a skin biopsy is taken at surgery. ${ }^{43}$ Typically, binding is absent in complete androgen insensitivity syndrome and binding affinity $\left(\mathrm{K}_{\mathrm{d}}\right)$ is altered in partial and mild androgen insensitivity syndrome. Genital skin fibroblasts can be used to identify genomic mutations that disrupt normal RNA splicing, quantify androgen receptor expression by western blots, and study the phenotypic variance recorded between patients with the same mutation. . $^{4,45}$

Automated DNA sequencing of the coding region and splice sites of the androgen receptor gene is now routinely available in the UK. A mutation is identified in more than $95 \%$ of patients with complete androgen insensitivity syndrome. The transcriptional activity of new mutant androgen receptors might need to be assessed, especially in patients with a phenotype for partial or mild disease. Information from functional assays has clinical relevance with regard to hormone treatment for patients with androgen insensitivity syndrome who were raised male. ${ }^{46,47}$ Androgen receptor function and mutations correlate somewhat in utero; this association is shown by the degree of external genital masculinisation. ${ }^{48}$ Transcriptional activity is generally absent or severely impaired on a physiological androgen basis in studies of androgen-receptor mutations associated with a phenotype of complete androgen insensitivity syndrome. The spontaneous mutation rate in complete androgen insensitivity syndrome is about $30 \%$ - a finding consistent with other X-linked recessive disorders such as haemophilia (due to factor VIII deficiency) and Duchenne muscular dystrophy. ${ }^{49}$ Most de-novo mutations are postzygotic and somatic mosaicism for the mutant androgen receptor can occur..$^{50}$ Phenotypic variation for the same mutation can occur and is noted within affected families. ${ }^{51,52}$

More than 800 mutations in different patients are entered in the Cambridge database of androgen receptor genes as of September, 2011. Most mutations of the androgen receptor gene are located within the ligandbinding domain. The most common functional androgen receptor defect results from disruption of the hydrophobic ligand-binding pocket, which is necessary for repositioning of helix 12 to form the activation function 2-coregulator interaction surface.

Most mutations of the ligand-binding domain that cause complete androgen insensitivity syndrome are situated between aminoacid residues 688 and 712, 739 and 784, and 827 and 870. The first two clusters cover most of the ligand-binding pocket. For example, a mutation in helix 5 changes the polar bulky arginine residue at codon 752 to glutamine (R752Q), resulting in loss of hydrogen bonding to the steroid A-ring ketone group of an androgen. ${ }^{53}$ This mutation also results in the spontaneous testicular feminisation rat model of complete androgen insensitivity syndrome..$^{54}$

The cluster of mutations between residue 827 and 870 map to subdomains distant from the ligand-binding pocket such as activation function 2 , a regulatory surface cleft termed binding function 3 , and a region that tethers the C-terminal tail of the receptor. ${ }^{55,56}$ The most common $\mathrm{C}$-terminal mutation reported in the androgen receptor (H917R) is associated with a phenotype of complete androgen insensitivity syndrome. ${ }^{57,58}$

The DNA-binding domain comprises 70 aminoacids and is highly conserved within the nuclear receptor family. The crystal structure of the domain when bound to DNA shows two zinc finger modules whose structure is dependent on cysteine interaction with the $\mathrm{Zn}^{2+}$ ion (figure 2). Any mutation of the cysteine residues would severely disrupt the zinc finger module structure and result in complete androgen insensitivity syndrome despite androgens binding normally to the ligandbinding domain. ${ }^{59,60}$ An $\alpha$ helix in the first zinc module (the proximal box) enters the major groove of doublestranded DNA and forms specific basepair contacts that are identical for all classical steroid receptors. ${ }^{61}$ Figure 2 shows the results of an androgen receptor functional 
assay for three different natural mutants when valine is replaced at codon 582 in the first zinc module. Transactivation of a reporter gene does not occur when valine is substituted for phenylalanine, and the phenotype is complete androgen insensitivity syndrome. By contrast, substitutions with glycine and leucine result in partial androgen responsiveness in vitro, which is shown by a phenotype of partial androgen insensitivity syndrome. The second zinc module includes the distal box, which is a receptor dimerisation motif comprising aminoacids 596-600. The outcome of mutations in this region of the DNA-binding domain is unpredictable. The Cambridge database of mutations of the androgen receptor gene records an I604S mutation just $\mathrm{C}$ terminal to the distal box in a pair of twins with complete androgen insensitivity syndrome (unpublished). A non-conservative substitution of the adjacent residue (D605Y) has been reported both in patients with partial androgen insensitivity syndrome who were raised male and in those with the syndrome who were raised female..$^{62,63}$

The activation function domain is the largest of the three domains, comprises 557 aminoacids, and is the least evolutionarily conserved. It has not been crystallised, but structure prediction and biochemical analysis suggest a disordered domain with intermittent regions of stable $\alpha$-helical structures. Audi and co-workers ${ }^{64}$ reported the only case of a phenotype of complete androgen insensitivity syndrome due to a single mis-sense mutation located in the activation function domain. Mis-sense mutations that do reside in the activation function domain are generally associated with a phenotype of mild androgen insensitivity syndrome. ${ }^{65}$

\section{Management}

\section{General management}

Management of androgen insensitivity syndrome should address functional, sexual, and psychological issues such as disclosure, gonadectomy and subsequent hormone replacement, creation of a functional vagina, and provision of genetic advice. Care needs to be individualised, flexible, and holistic. Management is dependent wholly on a multidisciplinary team. Membership of the team varies, but should include key members from endocrinology (paediatric or adult), urology, gynaecology, and clinical psychology. Additional input should be provided as necessary by specialists in neonatology, clinical genetics, medical ethics, and social services. A multidisciplinary approach is beneficial in terms of both optimum clinical management and education of health-care professionals. ${ }^{66-68}$ Patient advocacy groups (eg, the Androgen Insensitivity Syndrome Support Group and dsdFamilies in the UK) should have a close supportive role. Support groups related to androgen insensitivity syndrome are well represented in several countries.

The three categories of androgen insensitivity syndrome show phenotypes that can arise from several other
Panel 2: Classification of causes of disorders of sex development

Sex chromosome anomalies

- $45 X / 46, X Y$ (mixed gonadal dysgenesis)

- 46,XX/46,XY (chimerism)

- $47, X X Y$ (Klinefelter's syndrome)

$46, x x$

- Disorder of gonad development-eg, gonadal dysgenesis, ovotesticular disorders of sex development

- Fetal androgen excess-eg, congenital adrenal hyperplasia, aromatase deficiency, P450 oxidoreductase deficiency

- Maternal androgen excess-eg, luteoma of pregnancy

$46, X Y$

- Disorder of gonad development-eg, gonadal dysgenesis, ovotesticular disorders of sex development

- Disorder of androgen production-eg, mutation of the luteinising hormone receptor, $17 \beta$-hydroxysteroid dehydrogenase deficiency type 3, $5 \alpha$-reductase deficiency type 2

- Disorder of androgen action-eg, complete, partial, and mild androgen insensitivity syndromes

disorders, particularly with regard to partial disease. Many patients were traditionally labelled intersex (especially when the external genitalia are ambiguous at birth), but those affected and their families find the term pejorative. Consequently, a new nomenclature and classification system has been designed for disorders that cause genital abnormalities or a phenotype at variance with the genotype. This system is known as the Chicago Consensus, which discarded the term intersex in favour of the term disorder of sex development. ${ }^{69}$ Disorders of sex development are congenital disorders in which development of chromosomal, gonadal, or anatomical sex is atypical. The classification of causes of disorders of sex development is karyotype based and falls into three main categories: sex chromosome; 46,XY; and 46,XX (panel 2). Confusing terms such as male pseudohermaphrodite, female pseudohermaphrodite, and true hermaphrodite have been replaced by $46, \mathrm{XY}$ disorder of sex development, 46,XX disorder of sex development, and ovotesticular disorder of sex development, respectively. Thus, complete, partial, and mild androgen insensitivity syndromes fall in the generic category of $46, \mathrm{XY}$ disorder of sex development and represent disorders of androgen action.

These changes in long-standing terminology and the subsequent new classification system have been universally accepted by health professionals and scientists working in the specialty. ${ }^{70-72}$ A clear and uniform approach to the differential diagnosis of the causes of disorders of sex development is essential for initial management. In androgen insensitivity syndrome, management issues
For more on the Androgen Insensitivity Syndrome Support Group see http://www. aissg.org 


\section{Seminar}

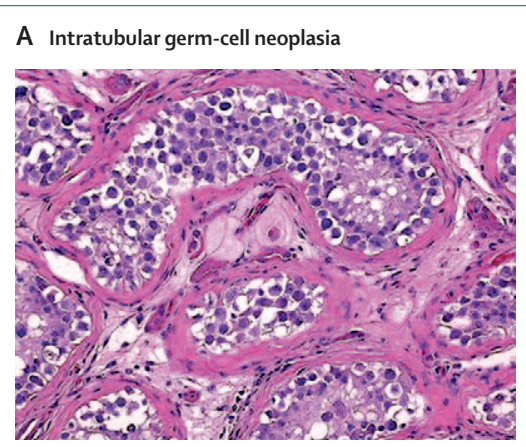

B Gonadoblastoma

C Dysgerminoma

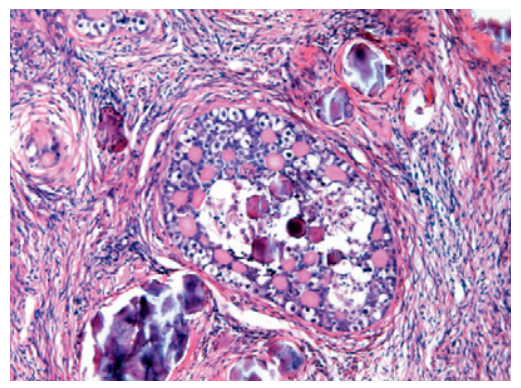

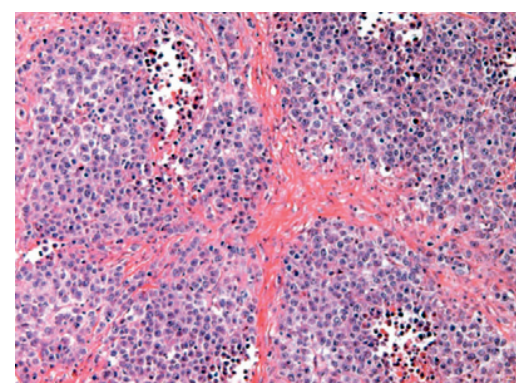

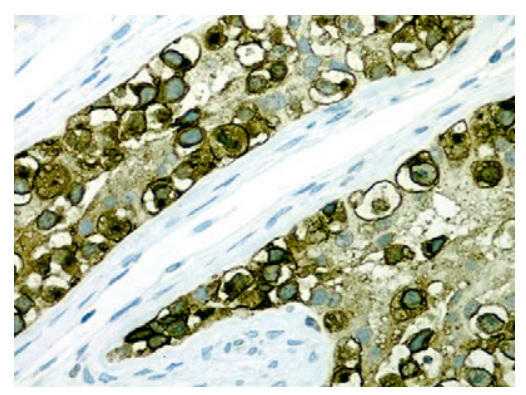

D Plap staining of carcinoma in situ

Figure 3: Gonadal tumours in complete androgen insensitivity syndrome

Representative examples of the histology of intratubular germ-cell neoplasia (or carcinoma in situ) (A), gonadoblastoma (B), and dysgerminoma (C) in gonads from patients with complete androgen insensitivity syndrome, and germ cells indicative of carcinoma in situ stained with placental-like alkaline phosphatase (PLAP; D).

vary according to age of presentation and whether the phenotype is for complete or partial disease.

\section{Complete androgen insensitivity syndrome}

The unexpected finding of a gonad during a hernia repair in a female infant prompts further investigation. ${ }^{73}$ Doctors should take a biopsy of the gonad at the time of hernia repair and resite it either subcutaneously or within the abdomen pending discussion with the parents about the diagnosis and plans for future management. ${ }^{1073}$ When complete androgen insensitivity presents in infancy, early gonadectomy with puberty induction later can be done, or gonadectomy can be delayed until early adulthood. Parents might choose early gonadectomy at a time when their child is unaware of the issues surrounding a diagnosis of complete androgen insensitivity syndrome. Their decision might be affected by the risk of gonadal tumour, even though the prevalence is very low in childhood..$^{74,75}$

What are the benefits of delaying gonadectomy until adolescence or young adulthood? Puberty occurs spontaneously within the normal age range for girls. It manifests as standard breast development and an appropriately timed growth spurt, but is not followed by menarche. If gonadectomy is done in childhood, puberty should be induced with oestrogen replacement. The principles are similar to induction of puberty in girls with Turner's syndrome. Ethinylestradiol is frequently used at a starting dose of $2 \mu \mathrm{g}$ daily from roughly 11 years of age. This dose is increased in increments of 2-4 $\mu \mathrm{g}$ over about 2 years to reach a daily dose of $30 \mu \mathrm{g}$ (unpublished). Thereafter, and in women who have a gonadectomy after puberty, several preparations are available, including the natural oestrogen estradiol, which can be given orally or transdermally. Synthetic oestrogens can be given in the form of the combined oral contraceptive pill. Some evidence supports the use of natural oestrogens as transdermal hormone replacement therapy because this administration method might be more physiological than oral delivery. ${ }^{76}$ However, selection of a preparation to suit the individual and therefore ensure compliance is probably more important than the type and route of administration. Since women with complete androgen insensitivity syndrome do not have a uterus, they can be treated with continuous, unopposed oestrogen. Some women also take supplementary testosterone because they think that it improves wellbeing (including libido). These effects might be oestrogen mediated from aromatisation of testosterone. Bone mineral density is reduced in complete androgen insensitivity syndrome, in keeping with the finding that androgens have a direct role in maintenance of bone density independent of oestrogens. ${ }^{7}$ No definitive evidence shows that bone mineral density is less affected in women who had late gonadectomies than in women who had early gonadectomies, although those who had the procedure later in life are substantially taller than those who had early gonadectomies. ${ }^{78,79}$ Women with complete androgen insensitivity syndrome do not seem to have an increased risk of fractures. Measurement of bone density at presentation in the case of young women with complete androgen insensitivity syndrome and at 2 yearly intervals is a useful index of the effectiveness of hormone replacement (unpublished).

If gonadectomy was not done in infancy, it is generally recommended in early adulthood to avoid the risk of gonadal tumours. The procedure is done laparoscopically if the gonads are intra-abdominal. Studies have suggested an increased tumour risk of greater than $30 \%$ in late adulthood if gonadectomy is not done, ${ }^{80}$ and a review ${ }^{81}$ of the risk of adult women with complete androgen insensitivity syndrome having a gonadal tumour could not be more specific than $0-22 \%$. Specific analyses in large sample groups suggest a germ-cell tumour risk as low as $0 \cdot 8-2 \%$, especially before puberty. ${ }^{74,75}$ Benign tumours of non-germ-cell origin include Sertoli cell adenoma and hamartomas.

Germ-cell tumours are classified into five categories on the basis of site of presentation, age, histology, and chromosomal constitution. ${ }^{82}$ Tumours associated with androgen insensitivity syndrome are in the type 2 category of seminoma, non-seminoma, and dysgerminoma. These tumours arise from a premalignant precursor called carcinoma in situ or intra-tubular germcell neoplasia, unclassified. ${ }^{83}$ Carcinoma in situ arises 
from gonocytes or primordial germ cells and is thought to be the result of a developmental arrest of fetal germ cells. It is characterised by an abundance of germ cells concentrated in the seminiferous tubules that stain positively for tumour markers-eg, placental-like alkaline phosphatase (figure 3), octamer-binding transcription factors 3 and 4 , and stem-cell factor. ${ }^{84}$ Carcinoma in situ leads to the development of a gonadoblastoma in more than $50 \%$ of cases. Some women with complete androgen insensitivity syndrome choose not to have a gonadectomy despite advice that the tumour risk might increase substantially in later adulthood..$^{81}$ Monitoring is based solely on imaging studies because none of the tumour markers is detectable in the circulation.

Vaginal surgery is rarely indicated for the creation of a functional vagina. Vaginal dilators are an effective firstline treatment; ${ }^{85}$ some women achieve a similar effect with sexual intercourse. Adults with complete androgen insensitivity syndrome rarely report sexual problems (although little evidence exists) once a reasonable vaginal length has been achieved. If surgery is needed, it should be delayed until consent is given and the woman is able to manage dilator therapy herself after surgery. ${ }^{86}$

Clitoral length and width are shorter in women with complete androgen insensitivity syndrome than in those without the disorder, presumably because of the absence of prenatal and postnatal action of androgens. . $^{87,88}$ Loss of fertility is a major issue for many women with complete androgen insensitivity syndrome. Individuals can adopt or might choose to use donor oocytes and a surrogate mother with their partner's sperm to achieve a pregnancy.

\section{Psychosocial management}

Psychosocial support is central to the multidisciplinary approach to management of complete androgen insensitivity syndrome. ${ }^{89}$ Presenting adolescents and parents of children with the disorder will have to make important decisions at diagnosis about treatments and the timing and extent of any surgical interventions. Concerns should focus on assimilation of the disconnect between chromosomal, gonadal, and phenotypic sex and its implications. Most centres caring for patients with disorders of sex development provide specialist psychological support. ${ }^{70}$

Historically, a paternalistic view about disclosure prevailed in disorders such as complete androgen insensitivity syndrome to protect families from shock and despair. ${ }^{5,90}$ This approach has largely been abandoned in favour of partial or full disclosure. ${ }^{91,92}$ One study ${ }^{93}$ that explored the emotional reactions of parents and adult patients to clinical diagnosis of androgen insensitivity syndrome showed a range of responses including shock, grief, and anger in both mothers and adult patients. An investigation ${ }^{94}$ of disorders of sex development in which adults with complete androgen insensitivity syndrome formed the largest diagnostic group, showed that younger women with the syndrome were better informed than were older women with the syndrome; many had full disclosure by 15 years of age. Many patients wished that they had been informed sooner than they had been about aspects of diagnosis, such as the presence of testes and the nature of the karyotype.

Disclosure must be done carefully, especially for children with complete androgen insensitivity syndrome as they approach pubertal age. Issues to address include implications of an XY karyotype, the presence of testes, absence of a uterus, infertility, and sexual function. Such information should be shared with parents initially, with age-appropriate disclosure as the child grows up. ${ }^{95}$ Mothers of girls with complete androgen insensitivity syndrome might feel a sense of guilt for having passed on the disorder and fear rejection after the facts are disclosed (unpublished). A heuristic approach to the ideas and components of sex development is a useful principle to adopt to understand physical and psychological sex-related development.

Long-term psychosexual outcome in complete androgen insensitivity syndrome suggests a trajectory of female-typical development, with the assimilation of a female identity and female-typical behaviour, and psychological wellbeing similar to that of other women. . $^{9697}$ Less positive outcomes have been reported for sexual functioning and sexual quality of life. ${ }^{98}$ Problems with desire, arousal, and dyspareunia were significant in a group of women with XY disorders of sex development, most of which were due to complete androgen insensitivity syndrome. ${ }^{99}$ Altered gender-related self-concept can be problematic, but might respond to psychological intervention. Difficulties with vaginal penetration can occur, but for many women with complete androgen insensitivity syndrome, the use of vaginal dilators and regular penetrative intercourse might correct the effects of vaginal hypoplasia.

\section{Partial androgen insensitivity syndrome}

Since the phenotype of partial androgen insensitivity syndrome generally presents as ambiguous genitalia in neonates, establishment of a diagnosis and reaching a decision on sex assignment and early management issues that need to be addressed are key. The phenotype of partial androgen insensitivity syndrome can result from several causes of XY disorders of sex development; thus definitive diagnosis relies on identification of a mutation in the androgen receptor gene that results in abnormal receptor function. Such information is seldom available before sex assignment. A short course of testosterone $(25 \mathrm{mg}$ intramuscularly monthly for 3 months) or topical dihydrotestosterone gel can be useful to determine androgen responsiveness. ${ }^{99}$

Most infants with partial androgen insensitivity syndrome are raised male. Little information is available about outcome at puberty. However, an external masculinisation score devised to quantify the degree of undermasculinisation in neonates with XY disorders of sex 
development ${ }^{100}$ might be a reasonable predictor of virilisation at puberty in infants with partial androgen insensitivity syndrome who were assigned male (unpublished). Androgen supplementation might be needed at puberty in patients with androgen resistance, but is not alway necessary. Surgery is done during the second to third year of life to repair hypospadias and bring undescended testes into the scrotum. Gynaecomastia often occurs in adolescence, and requires reduction mammoplasty. Breast cancer can occur rarely in men with partial androgen insensitivity syndrome. ${ }^{101}$ By contrast, apart from a case report of a juvenile fibroadenoma of the breast in a young woman, ${ }^{102}$ no reports seem to exist of breast cancer in women with complete androgen insensitivity syndrome.

An infant with partial androgen insensitivity syndrome who is assigned female will need a genitoplasty procedure and gonadectomy before puberty to avoid the risk of virilisation. Oestrogen replacement is needed to induce female puberty. The risk of germ-cell tumours is higher in partial than in complete androgen insensitivity syndrome, with a suggested incidence of $15 \%$ and even higher if the testes are not scrotal in position. ${ }^{103}$ Psychological distress is more common in adults with partial androgen insensitivity syndrome than in those with complete androgen insensitivity syndrome, irrespective of whether they were raised male or female. In one study of men with partial androgen insensitivity syndrome, all aspects of sexual activity were substantially impaired. ${ }^{104}$ However, outcome studies are few and comprise small numbers. Studies with large sample sizes that use standardised and validated measures of sexual function are needed. Even less information is available in patients with mild androgen insensitivity syndrome, but individuals might need reduction mammoplasty for gynaecomastia and supplemental androgens to treat oligospermia.

To improve diagnosis and management of all causes of XY disorders of sex development (including complete and particularly partial androgen insensitivity syndromes), multicentre collaboration at national and

For more on the EuroDSD consortium see http://www. eurodsd.eu

For the I-DSD registy see https:// tethys.nesc.gla.ac.uk international levels is needed. The EuroDSD consortium, which has a register of more than 1000 cases, is a promising start, and has evolved internationally to become the I-DSD registry. Almost a third of the cases on the European register are associated with disorders of androgen action.

\section{Contributors}

IAH conceived the framework for the Seminar; wrote the introduction, the section about mechanism of androgen action, and part of the management section; and coordinated the final report. JDD and TIB wrote the molecular pathogenesis section and made the related figures, VP and KM contributed the psychology section, and JM contributed aspects of the management section.

Conflicts of interest

IAH has received lecture fees and travel grants from Pfizer, Novo Nordisk, Ferring, Merck Serono, and Ipsen. All other authors declare that they have no conflicts of interest.

\section{Acknowledgments}

Many of the studies described in this Seminar were undertaken as part of the NIHR Cambridge Biomedical Research Centre. Support for part of the research was received from Newlife (formerly Birth Defects Foundation) and an EC FP7 programme grant (No 201444) to fund the Cambridge centre within EuroDSD. We thank Becky Treacy and her colleagues in the Molecular Genetics Service Laboratory who did much of the routine androgen receptor gene sequencing, Norma Coggins who supervised the Cambridge database, and Pam Stockham and Louise Goode who coordinated production of the report.

References

1 Jameson LJ. Hormone resistance syndromes. Human Press 1999; $1-281$.

2 Semple RK, Savage DB, Cochran EK, Gorden P, O'Rahilly S. Genetic syndromes of severe insulin resistance. Endocr Rev 2011; 32: 498-514.

3 Huhtaniemi I, Alevizaki M. Mutations along the hypothalamic-pituitary-gonadal axis affecting male reproduction. Reprod Biomed Online 2007; 15: 622-32.

4 Achermann JC, Hughes IA. Disorders of sex development. In: Kronenberg HM, Melmed S, Polonsky KS, Larsen PR, eds. Williams Textbook of Endocrinology, 12th edn. Philadelphia: Saunders Elsevier, 2011: 863-94.

5 Morris JM. The syndrome of testicular feminization in male pseudohermaphrodites. Am J Obstet Gynecol 1953; 65: 1192-211.

6 Quigley CA, De Bellis A, Marschke KB, el-Awady MK, Wilson EM, French FS. Androgen receptor defects: historical, clinical, and molecular perspectives. Endocr Rev 1995; 16: 271-321.

7 Boehmer AL, Brinkmann O, Brüggenwirth H, et al. Genotype versus phenotype in families with androgen insensitivity syndrome. J Clin Endocrinol Metab 2001; 86: 4151-60.

8 Sarpel U, Palmer SK, Dolgin SE. The incidence of complete androgen insensitivity in girls with inguinal hernias and assessment of screening by vaginal length measurement. J Pediatr Surg 2005; 40: 133-37.

9 Hurme T, Lahdes-Vasama T, Mäkela E, Iber T, Toppari J. Clinical findings in prepubertal girls with inguinal hernia with special reference to the diagnosis of androgen insensitivity syndrome. Scand J Urol Nephrol 2009; 43: 42-46.

10 Deeb A, Hughes IA. Inguinal hernia in female infants: a cue to check the sex chromosomes? BJU Int 2005; 96: 401-03.

11 Chiu RW, Lo YM, Lo D. Non-invasive prenatal diagnosis by fetal nucleic acid analysis in maternal plasma: the coming of age. Semin Fetal Neonatal Med 2011; 16: 88-93.

12 Yalinkaya A, Yayla M, Erdemoglu M. Prenatal diagnosis of a fetus with androgen insensitivity syndrome (AIS). Prenat Diagn 2007; 27: 856-57.

13 Stewart CJR, Baker E, Beaton C, Crook M, Peverall J, Wallace S Detection of Y-chromosome in gonadal tumours using fluorescence in situ hybridization: diagnostic value in intersex conditions including older patients with clinically unsuspected androgen insensitivity syndrome. Histopathology 2008; 52: 175-82.

14 Danilovic DLS, Correa PHS, Costa EMF, Melo KFS, Mendonca BB, Arnhold IJP. Height and bone mineral density in androgen insensitivity syndrome with mutations in the androgen receptor gene. Osteoporos Int 2007; 18: 369-74.

15 Han TS, Goswami D, Trikudanathan S, Creighton SM, Conway GS. Comparison of bone mineral density and body proportions between women with complete androgen insensitivity syndrome and women with gonadal dysgenesis. Eur J Endocrinol 2008; 159: 179-85.

16 Papadimitriou DT, Linglart A, Morel Y, Chaussain J-L. Puberty in subjects with complete androgen insensitivity syndrome. Horm Res 2006; 65: 126-31.

17 Lango Allen H, Estrada K, Lettre G, et al. Hundreds of variants clustered in genomic loci and biological pathways affect human height. Nature 2010; 467: 832-38.

18 Miles HL, Gidlöf S, Nordenström A, Ong KK, Hughes IA. The role of androgens in fetal growth: observational study in two genetic models of disordered androgen signalling. Arch Dis Child Fetal Neonatal Ed 2010; 95: F435-38.

19 Melo KFS, Mendonca BB, Billerbeck AEC, et al. Clinical, hormonal, behavioral, and genetic characteristics of androgen insensitivity syndrome in a Brazilian cohort: five novel mutations in the androgen receptor gene. J Clin Endocrinol Metab 2003; 88: 3241-50. 
20 Hughes IA, Deeb A. Androgen resistance. Best Pract Res Clin Endocrinol Metab 2006; 20: 577-98.

21 Sinnecker GH, Hiort O, Nitsche EM, Holterhus PM, Kruse K, and the German Collaborative Intersex Study Group. Functional assessment and clinical classification of androgen sensitivity in patients with mutations of the androgen receptor gene. Eur J Pediatr 1997; 156: 7-14.

22 Bouvattier C, Carel JC, Lecointre C, et al. Postnatal changes of T, $\mathrm{LH}$, and FSH in 46,XY infants with mutations in the AR gene. J Clin Endocrinol Metab 2002; 87: 29-32.

23 Quigley CA. Editorial: The postnatal gonadotropin and sex steroid surge-insights from the androgen insensitivity syndrome. J Clin Endocrinol Metab 2002; 87: 24-28.

24 Bergadá I, Milani C, Bedecarrás P, et al. Time course of the serum gonadotropin surge, inhibins, and anti-Müllerian hormone in normal newborn males during the first month of life. J Clin Endocrinol Metab 2006; 91: 4092-98.

25 Bay K, Virtanen HE, Hartung S, et al, and the Nordic Cryptorchidism Study Group. Insulin-like factor 3 levels in cord blood and serum from children: effects of age, postnatal hypothalamic-pituitary-gonadal axis activation, and cryptorchidism. J Clin Endocrinol Metab 2007; 92: 4020-27.

26 Ahmed SF, Keir L, McNeilly J, Galloway P, O’Toole S, Wallace AM. The concordance between serum anti-Mullerian hormone and testosterone concentrations depends on duration of hCG stimulation in boys undergoing investigation of gonadal function. Clin Endocrinol (Oxf) 2010; 72: 814-19.

27 Aksglaede L, Sørensen K, Boas M, et al. Changes in anti-Müllerian hormone $(\mathrm{AMH})$ throughout the life span: a population-based study of 1027 healthy males from birth (cord blood) to the age of 69 years. J Clin Endocrinol Metab 2010; 95: 5357-64.

28 Rey R, Mebarki F, Forest MG, et al. Anti-müllerian hormone in children with androgen insensitivity. J Clin Endocrinol Metab 1994; 79: 960-64.

29 Boukari K, Meduri G, Brailly-Tabard S, et al. Lack of androgen receptor expression in Sertoli cells accounts for the absence of anti-mullerian hormone repression during early human testis development. J Clin Endocrinol Metab 2009; 94: 1818-25.

30 Michala L, Goswami D, Creighton SM, Conway GS. Swyer syndrome: presentation and outcomes. BJOG 2008; 115: 737-41.

31 Pittock ST, Babovic-Vuksanovic D, Lteif A Mayer-Rokitansky-Küster-Hauser anomaly and its associated malformations. Am J Med Genet A 2005; 135: 314-16.

32 Faisal SF, Achermann JC, Arlt W, et al. UK guidance on the initial evaluation of an infant of an adolescent with a suspected disorder of sex development. Clin Endocrinol 2011; published online April 16. DOI:10.1111/j.1365-2265.2011.04076.x.

33 Veiga-Junior NN, Medeats PAR, Petroli RJ, et al. Clinical and laboratorial features that may differentiate $46, \mathrm{XY}$ DSD due to partial androgen insensitivity and $5 \alpha$-reductase type 2 deficiency. Int J Endocrinol 2012; published online Dec 12. DOI:10.1155/2012/964876.

34 Zuccarello D, Ferlin A, Vinanzi C, et al. Detailed functional studies on androgen receptor mild mutations demonstrate their association with male infertility. Clin Endocrinol (Oxf) 2008; 68: 580-88.

35 Yong EL, Ng SC, Roy AC, Yun G, Ratnam SS. Pregnancy after hormonal correction of severe spermatogenic defect due to mutation in androgen receptor gene. Lancet 1994; 344: 826-27.

36 Wang RS, Yeh S, Tzeng CR, Chang C. Androgen receptor roles in spermatogenesis and fertility: lessons from testicular cell-specific androgen receptor knockout mice. Endocr Rev 2009; 30: 119-32.

37 Finsterer J. Bulbar and spinal muscular atrophy (Kennedy's disease): a review. Eur J Neurol 2009; 16: 556-61.

38 La Spada AR, Wilson EM, Lubahn DB, Harding AE, Fischbeck KH. Androgen receptor gene mutations in X-linked spinal and bulbar muscular atrophy. Nature 1991; 352: 77-79.

39 Thomas PS Jr, Fraley GS, Damian V, et al. Loss of endogenous androgen receptor protein accelerates motor neuron degeneration and accentuates androgen insensitivity in a mouse model of X-linked spinal and bulbar muscular atrophy. Hum Mol Genet 2006; 15: 2225-38.

40 Voorhoeve PG, van Mechelen W, Uitterlinden AG, Delemarre-van de Waal HA, Lamberts SW. Androgen receptor gene CAG repeat polymorphism in longitudinal height and body composition in children and adolescents. Clin Endocrinol (Oxf) 2011; 74: 732-35.
41 Werner R, Holterhus PM, Binder G, et al. The A645D mutation in the hinge region of the human androgen receptor (AR) gene modulates AR activity, depending on the context of the polymorphic glutamine and glycine repeats. J Clin Endocrinol Metab 2006; 91: 3515-20.

42 Matias PM, Donner P, Coelho R, et al. Structural evidence for ligand specificity in the binding domain of the human androgen receptor. Implications for pathogenic gene mutations. J Biol Chem 2000; 275: 26164-71.

43 Evans BAJ, Jones TR, Hughes IA. Studies of the androgen receptor in dispersed fibroblasts: investigation of patients with androgen insensitivity. Clin Endocrinol (Oxf) 1984; 20: 93-105.

44 Wang $M$, Wang J, Zhang Z, et al. Dissecting phenotypic variation among AIS patients. Biochem Biophys Res Commun 2005; 335: 335-42.

45 Holterhus PM, Deppe U, Werner R, et al. Intrinsic androgen-dependent gene expression patterns revealed by comparison of genital fibroblasts from normal males and individuals with complete and partial androgen insensitivity syndrome. BMC Genomics 2007; 8: 376.

46 Szafran AT, Hartig S, Sun H, et al. Androgen receptor mutations associated with androgen insensitivity syndrome: a high content analysis approach leading to personalized medicine. PLoS One 2009; 4: e8179.

47 Lundberg Giwercman Y, Nikoshkov A, Lindsten K, et al. Response to treatment in patients with partial androgen insensitivity due to mutations in the DNA-binding domain of the androgen receptor. Horm Res 2000; 53: 83-88.

48 Tadokoro R, Bunch T, Schwabe JW, Hughes IA, Murphy JC. Comparison of the molecular consequences of different mutations at residue 754 and 690 of the androgen receptor (AR) and androgen insensitivity syndrome (AIS) phenotype. Clin Endocrinol (Oxf) 2009; 71: 253-60.

49 Leslie ND. Haldane was right: de novo mutations in androgen insensitivity syndrome. J Pediatr 1998; 132: 939-43.

50 Köhler B, Lumbroso S, Leger J, et al. Androgen insensitivity syndrome: somatic mosaicism of the androgen receptor in seven families and consequences for sex assignment and genetic counseling. J Clin Endocrinol Metab 2005; 90: 106-11.

51 Evans BA, Hughes IA, Bevan CL, Patterson MN, Gregory JW. Phenotypic diversity in siblings with partial androgen insensitivity syndrome. Arch Dis Child 1997; 76: 529-31.

52 Holterhus PM, Sinnecker GH, Hiort O. Phenotypic diversity and testosterone-induced normalization of mutant L712F androgen receptor function in a kindred with androgen insensitivity. J Clin Endocrinol Metab 2000; 85: 3245-50.

53 Cheikhelard A, Morel Y, Thibaud E, et al. Long-term followup and comparison between genotype and phenotype in 29 cases of complete androgen insensitivity syndrome. J Urol 2008; 180: 1496-501.

54 Yarbrough WG, Quarmby VE, Simental JA, et al. A single base mutation in the androgen receptor gene causes androgen insensitivity in the testicular feminized rat. J Biol Chem 1990; 265: 8893-900.

55 Estebanez-Perpina E, Arnold LA, Nguyen P, et al. A surface on the androgen receptor that allosterically regulates coactivators binding. Proc Natl Acad Sci USA 2007; 10: 16074-79.

56 Tahiri B, Auzou G, Nicolas JC, Sultan C, Lupo B. Participation of critical residues from the extreme C-terminal end of the human androgen receptor in the ligand binding function. Biochemistry 2001; 40: 8431-37.

57 Ahmed SF, Cheng A, Dovey L, et al. Phenotypic features, androgen receptor binding, and mutational analysis in 278 clinical cases reported as androgen insensitivity syndrome. J Clin Endocrinol Metab 2000; 85: 658-65.

58 Werner R, Zhan J, Gesing J, Struve D, Hiort O. In-vitro characterization of androgen receptor mutations associated with complete androgen insensitivity syndrome reveals distinct functional deficits. Sex Dev 2008; 2: 73-83.

59 Hughes IA, Evans BA. Complete androgen insensitivity syndrome characterized by increased concentration of a normal androgen receptor in genital skin fibroblasts. J Clin Endocrinol Metab 1986; 63: $309-15$

60 Quigley CA, Evans BA, Simental JA, et al. Complete androgen insensitivity due to deletion of exon $\mathrm{C}$ of the androgen receptor gene highlights the functional importance of the second zinc finger of the androgen receptor in vivo. Mol Endocrinol 1992; 6: 1103-12. 
61 Gewirth DT, Sigler PB. The basis for half-site specificity explored through a non-cognate steroid receptor-DNA complex. Nat Struct Biol 1995; 2: 386-94.

62 Hiort O, Wodtke A, Struve D, Zöllner A, Sinnecker GH, and the German Collaborative Intersex Study Group. Detection of point mutations in the androgen receptor gene using non-isotopic single strand conformation polymorphism analysis. Hum Mol Genet 1994; 3: 1163-66.

63 Scheiber D, Barta C, Halász Z, et al. Mutational analysis of Hungarian patients with androgen insensitivity syndrome. J Pediatr Endocrinol Metab 2003; 16: 367-73.

64 Audi L, Fernández-Cancio M, Carrascosa A, et al, and the Grupo de Apoyo al Síndrome de Insensibilidad a los Andrógenos (GrApSIA). Novel $(60 \%)$ and recurrent $(40 \%)$ androgen receptor gene mutation in a series of 59 patients with a 46,XY disorder of sex development. J Clin Endocrinol Metab 2010; 95: 1876-88.

65 Zuccarello D, Ferlin A, Vinanzi C, et al. Detailed functional studies on androgen receptor mild mutations demonstrate their association with male infertility. Clin Endocrinol (Oxf) 2008; 68: 580-88.

66 Brain CE, Creighton SM, Mushtaq I, et al. Holistic management of DSD. Best Pract Res Clin Endocrinol Metab 2010; 24: 335-54.

67 Douglas G, Axelrod ME, Brandt ML, at al. Consensus in guidelines for evaluation of DSD by the Texas Children's Hospital Multidisciplinary Gender Medicine Team. Int J Ped Endocrinol 2010: 919707.

68 Houk CP, Lee PA. Update on disorders of sex development. Curr Opin Endocrinol Diabetes Obes 2012; 19: 28-32.

69 Hughes IA, Houk C, Ahmed SF, Lee PA, and the LWPES Consensus Group, and the ESPE Consensus Group. Consensus statement on management of intersex disorders. Arch Dis Child 2006; 91: 554-63.

70 Pasterski V, Prentice P, Hughes IA. Consequences of the Chicago consensus on disorders of sex development (DSD): current practices in Europe. Arch Dis Child 2010; 95: 618-23.

71 Davies JH, Knight EJ, Savage A, Brown J, Malone PS. Evaluation of terminology used to describe disorders of sex development J Pediatr Urol 2011; 7: 412-15.

72 Hughes IA. The quiet revolution: disorders of sex development. Best Pract Res Clin Endocrinol Metab 2010; 24: 159-62.

73 Kim ES, Warner BW. Unexpected finding during inguinal hernia repair in a girl. Surgery 2005; 138: 954-55.

74 Hannema SE, Scott IS, Rajpert-De Meyts E, Skakkebaek NE, Coleman N, Hughes IA. Testicular development in the complete androgen insensitivity syndrome. J Pathol 2006; 208: 518-27.

75 Looijenga LHJ, Hersmus R, Oosterhuis JW, Cools M, Drop SLS, Wolffenbuttel KP. Tumor risk in disorders of sex development (DSD). Best Pract Res Clin Endocrinol Metab 2007; 21: 480-95.

76 Illig R, DeCampo C, Lang-Muritano MR, et al. A physiological mode of puberty induction in hypogonadal girls by low dose transdermal 17 beta-oestradiol. Eur J Pediatr 1990; 150: 86-91.

77 Danilovic DL, Correa PH, Costa EM, Melo KF, Mendonca BB, Arnhold IJ. Height and bone mineral density in androgen insensitivity syndrome with mutations in the androgen receptor gene. Osteoporos Int 2007; 18: 369-74.

78 Bertelloni S, Baroncelli GI, Mora S. Bone health in disorders of sex differentiation. Sex Dev 2010; 4: 270-84.

79 Han TS, Goswami D, Trikudanathan S, Creighton SM Conway GS. Comparison of bone mineral density and body proportions between women with complete androgen insensitivity syndrome and women with gonadal dysgenesis. Eur J Endocrinol 2008; 159: 179-85.

80 Rutgers JL, Scully RE. The androgen insensitivity syndrome (testicular feminization): a clinicopathologic study of 43 cases. Int J Gynecol Pathol 1991; 10: 126-44.

81 Deans R, Creighton SM, Liao LM, Conway GS. Timing of gonadectomy in adult women with complete androgen insensitivity syndrome: patient preferences and clinical evidence. Clin Endocrinol 2012; published online Jan 2. DOI:10:1111/13652265/2012/04330.

82 Looijenga LHJ, Hersmus R, de Leeuw BHCGM, et al. Gonada tumours and DSD. Best Pract Res Clin Endocrinol Metab 2010; 24: 291-310.
83 Rajpert-de Meyts E, Hoei-Hansen CE. From gonocytes to testicular cancer: the role of impaired gonadal development. Ann N Y Acad Sci 2007; 1120: 168-80.

84 Looijenga LH, Gillis AJ, Stoop H, Biermann K, Oosterhuis JW. Dissecting the molecular pathways of (testicular) germ cell tumour pathogenesis; from initiation to treatment-resistance. Int $J$ Androl 2011; 34: e234-51.

85 Ismail-Pratt IS, Bikoo M, Liao LM, Conway GS, Creighton SM. Normalization of the vagina by dilator treatment alone in Complete Androgen Insensitivity Syndrome and Mayer-Rokitansky-KusterHauser Syndrome. Hum Reprod 2007; 22: 2020-24.

86 Purves JT, Miles-Thomas J, Migeon C, Gearhart JP. Complete androgen insensitivity: the role of the surgeon. J Urol 2008; 180 (suppl): 1716-19.

87 Crouch NS, Michala L, Creighton SM, Conway GS. Androgendependent measurements of female genitalia in women with complete androgen insensitivity syndrome. BJOG 2011; 118: 84-87.

88 Wilson JM, Arnhym A, Champeau A, Ebbers M, Coakley F, Baskin L. Complete androgen insensitivity syndrome: an anatomic evaluation and sexual function questionnaire pilot study. J Pediatr Urol 2011; 7: 416-21.

89 Liao L-M. Learning to assist women with atypical genitalia: journey through ignorance, taboo and dilemma. J Reprod Infant Psychol 2003; 21: 229-38.

90 Shah R, Woolley MM, Costin G. Testicular feminization: the androgen insensitivity syndrome. J Pediatr Surg 1992; 27: 757-60.

91 Jorgensen PB, Kjartansdóttir KR, Fedder J. Care of women with XY karyotype: a clinical practice guideline. Fertil Steril 2010; 94: 105-13.

92 Liao L-M, Tacconelli E, Wood D, Conway G, Creighton SM. Adolescent girls with disorders of sex development: a needs analysis of transitional care. J Pediatr Urol 2010; 6: 609-13.

93 Slijper FM, Frets PG, Boehmer AL, Drop SL, Niermeijer MF. Androgen insensitivity syndrome (AIS): emotional reactions of parents and adult patients to the clinical diagnosis of AIS and its confirmation by androgen receptor gene mutation analysis. Horm Res 2000; 53: 9-15.

94 Liao L-M, Green H, Creighton SM, Crouch NS, Conway GS Service users' experiences of obtaining and giving information about disorders of sex development. BJOG 2010; 117: 193-99.

95 Goodall J. Helping a child to understand her own testicular feminisation. Lancet 1991; 337: 33-35.

96 Hines M, Ahmed SF, Hughes IA. Psychological outcomes and gender-related development in complete androgen insensitivity syndrome. Arch Sex Behav 2003; 32: 93-101.

97 Cohen-Kettenis PT. Psychosocial and psychosexual aspects of disorders of sex development. Best Pract Res Clin Endocrinol Metab 2010; 24: 325-34.

98 Minto CL, Liao KL, Conway GS, Creighton SM. Sexual function in women with complete androgen insensitivity syndrome. Fertil Steril 2003; 80: 157-64.

99 Hughes IA. Early management and gender assignment in disorders of sexual differentiation. Endocr Dev 2007; 11: 47-57.

100 Ahmed SF, Khwaja O, Hughes IA. The role of a clinical score in the assessment of ambiguous genitalia. BJU Int 2000; 85: 120-24.

101 Poujol N, Lobaccaro JM, Chiche L, Lumbroso S, Sultan C. Functional and structural analysis of R607Q and R608K androgen receptor substitutions associated with male breast cancer. Mol Cell Endocrinol 1997; 130: 43-51.

102 Davis SE, Wallace AM. A 19 year old with complete androgen insensitivity syndrome and juvenile fibroadenoma of the breast. Breast J 2001; 7: 430-33.

103 Cools M, Drop SLS, Wolffenbuttel KP, Oosterhuis JW, Looijenga LHJ. Germ cell tumors in the intersex gonad: old paths, new directions, moving frontiers. Endocr Rev 2006; 27: 468-84.

104 Bouvattier C, Mignot B, Lefèvre H, Morel Y, Bougnères P. Impaired sexual activity in male adults with partial androgen insensitivity. J Clin Endocrinol Metab 2006; 91: 3310-15. 